\title{
Compulsive Consumers: Mindfulness in Social Skills Training
}

\author{
Agnes Altmann ${ }^{1 *}$ and Mellina Terres ${ }^{2}$ \\ 1Master's student in the Graduate Program in Information Technology and Health Management at the Federal University of Health Sciences of Porto Alegre, \\ Brazil \\ 2Teacher of the Graduate Program in Psychology at the Federal University of Health Sciences of Porto Alegre, Brazil
}

*Corresponding author: Agnes Altmann, Master's student in the Graduate Program in Information Technology and Health Management at the Federal University of Health Sciences of Porto Alegre, Brazil

To Cite This Article: Agnes Altmann, Compulsive Consumers: Mindfulness in Social Skills Training. 2020 - 7(4). AJBSR.MS.ID.001179.

DOI: 10.34297/AJBSR.2020.07.001179.

Received: 此 February 05, 2020; Published: 眥 February 26, 2020

\begin{abstract}
The state of consciousness that involves attention to experiences, moment by moment, in a receptive and non-judgmental manner is characterized as mindfulness or mindfulness. The mindfulness construct has been extensively researched, mainly in clinical studies and more recently in its impact on social habits and consumerism. So, how can mindfulness contribute to changing exacerbated consumption habits? This study presents a reflection on the state and practice of mindfulness through a bibliographic review in recent articles, related to the context of consumption and the social environment. In this way, we understand the society in which consumer relations are in an accelerated process, while they aim at progress, they face a narcissistic moment, in search of constant satisfaction, generating an individualist reflex.
\end{abstract}

Thus, it demonstrates a possible point of convergence, in which mindfulness can minimize a certain influence on another, either by social bias, by the significance of brands and media disclosures (cause), or by consumerism. So, how can mindfulness be an effective way of preparing people to face the challenges of consumerism daily? The results of the researches show that the practice of mindfulness can help in controlling the satisfaction of consumption activities, emotional regulation, reduction of emotional stress, improvement of social involvement and increase in personal bonds. Likewise, these benefits can extend to well-being, both emotional and health, generating a better quality of life.

Keywords: Consumerism, Social skills, Mindfulness, Narcissistic moment, Cognitive assessments, Compulsive Consumers, Oniomania, Anxiety, Compulsion, Muscle relaxation

\section{Introduction}

Consumption can be understood as the act or the effect of consuming, it is an element of biological survival, although it is an active part of the psychological of people and is among the most basic and remote activities of the human being [1]. One can live without producing, but living without consuming becomes a very difficult situation, since human beings depend on consumption to guarantee their survival [2]. Understood as a characteristically individual activity, it can be verified that it occurs in a public way-as in the consumption of health services. transport and health, for example-and, in the same way, it may have a profile of resource depletion: "Consumption is divided between a supply and expenditure activity, in an analogy both to what it nourishes and feeds and to what it exhausts and destroys [3]".

\section{Compulsive Consumers / ONIOMANIA / TCC}

The way in which people make their purchasing decisions based only on rational criteria or cognitive assessments of market options has lost space for lines that claim that purchasing relationships are strongly influenced by behavioral optics. The consumption process is related to the variations between supply and demand and the rational consumer has been replaced by the influence of thoughts, attitudes, expectations and feelings intrinsic to this process $[4,5]$.

\section{Compulsion, Anxiety and Mindfulness Actions}

It is known that high levels of anxiety can impair the use of HS, preventing the subject from issuing a socially adequate response [7-9]. Thus, it is indicated the inclusion of techniques that help 
to reduce anxiety in consumerism, in order to potentiate the intervention so that the learned repertoire is put into practice [7] Anxiety reduction strategies are used from the identification of signs of anxiety, to exercises aimed at muscle relaxation and images that deepen the state of relaxation [7].

\section{Final Considerations}

It is concluded that the use of mindfulness techniques in the context of sustainable consumption can bring benefits to the participants, increasing the capacity for emotional regulation and the awareness of the internal and external experience. These attributes enable an increase in the ability to perform daily tasks, to deal with emotions such as anxiety, helping with mental health Also, mindfulness can contribute to better performance and learning in everyday tasks.

\section{References}

1. Baudrillhard J (1996) The consumer society. $70^{\text {th }}(E d n)$, Lisbon, Prtugal.

2. Barbosa L (2004) Consumer society. Jorge Zahar Ed, Rio de Janeiro, Brazil.
3. Bauman ZA (2008) Consumer Society. Portugal 70.

4. Barros VV, Kozasa EH, Souza ICW, Ronzani TM (2015) Validity evidence of the Brazilian version of the Mindful Attention Awareness Scale (MAAS). Psychology Reflection and Criticism 28(1): 87-95.

5. Beauchemin J, Hutchins TL, Patterson F (2008) Mindfulness Meditation May Lessen Anxiety, Promote Social Skills, and Improve Academic Performance Among Adolescents with Learning Disabilities. Sage 13(1): 34-45.

6. Bowen S, Chawla N, Marlatt GA (2011) Mindfulness-based relapse prevention for addictive behaviors: A clinician's guide. The Guilford Press. New York, USA.

7. Caballo VE (1987) Evaluation of social skills: a multimodal strategy. Doctoral Thesis, Autonomous University of Madrid, Madrid, Spain.

8. Caballo VE (2003) Social skills assessment and training manual. São Paulo, Livraria Santos, Brazil.

9. Cardaciotto L, Herbert JD, Forman EM, Moitra E, Farrow V (2008) The assessment of present-moment awareness and acceptance: the Philadelphia Mindfulness Scale. Assessment 15(2): 204-223. 